Pisancheva, B. (2020). Models in Lace. Eurasia: current issues of cultural heritage. Collection of Scientific Articles. European Scientific e-Journal, 3 (3), 73-88. Hlučín-Bobrovníky: “Anisiia Tomanek” OSVČ.

Писанчева, Б (2020). Модели в дантелата. Eurasia: current issues of cultural heritage. Collection of Scientific Articles. European Scientific e-Journal, 3 (3), 73-88. Hlučín-Bobrovníky: “Anisiia Tomanek" OSVČ.

DOI: $10.47451 /$ art2020-11-001

EOI: $10.11244 / \operatorname{art} 2020-11-001$

The paper is published in Crossref, Internet Archive, Google Scholar, Academic Resource Index ResearchBib, JGate, ISI, CiteFactor, ICI, eLibrary databases.

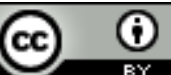

Bistra Pisancheva

Lacemaker, Member of OIDFA

Doctoral student Interpretative Anthropology MA Program

Bulgarian Literature Department

Faculty of Slavic Studies

St Kliment Ohridski Sofia University

Sofia, Bulgaria

E-mail: bistrapisancheva@gmail.com

\title{
Models in Lace
}

\section{Abstract:}

In the past, lacemaking was a craft practiced by thousands of lacemakers who produced material for decorating the clothes and homes of wealthy aristocrats. Nowadays, the making of lace is defined as an applied art. The article interprets the making bobbin lace through the Theory of Models. Selected details from the technological process of creating the different types and styles of the final products illustrate the idea of following a model while transferring meaning from one field of art into another. The author concludes that the representation of lacemaking as a model of technological processes, of lace items, and a community of people who practice this handcraft, could contribute to the preservation of this part of the immaterial cultural heritage of humanity.

\section{Keywords:}

Cultural technologies, model theory, social practices, bobbin lace, safeguarding tradition, fashion, contemporary interpretations.

Бистра Писанчева Аантелиер, член на OIDFA

Аокторант

Магистьрска програма Интерпретативна антропология

КатеАра Бъмгарска митература

Факултет Славянски филологии Софийски Университет “Св. КАимент Охридски” София, Бъмгария E-mail: bistrapisancheva@gmail.com 


\title{
Модели в дантелата
}

\begin{abstract}
Aнотачия:
В миналото Аантеленото плаване е било занаят, практикуван от хиляди Аантели, произвеждащи материал за украса на дрехи и домове на богати аристократи. Анес производството на Аантела се определя като прицожно изкуство. В тази статия правенето на Аантела на совалки се интерпретира чрез теорията на моделите. Подбрани детайли от технологичния процес на създаване Ао разАичните видове стилове в произведените изделия илюстрират идеята за следване на модел при прехвърляне на смисъц от една област на изкуството в Аруга. Авторьт заключава, че представянето на Аантелата като модел на технологични процеси, Аантели и общност от хора, практикуващи този занаят, може Аа Аопринесе за запазването на тази част от нематериалното културно наследство на човечеството.
\end{abstract}

Ключови думи:

Културни технологии, теория на моделите, социални практики, Аантела на совалки, съхраняване на традицията, мода, съвременни интерпретации.

\section{Introduction}

In the past, lacemaking was a craft practiced by thousands of lacemakers who produced material for decorating the clothes and homes of wealthy aristocrats. Nowadays, the making of lace is defined as an applied art.

It is difficult to describe such centuries-long human activity in a nutshell. German-born American anthropologist and pioneer of modern anthropology Franz Boas (1896-1982) talks about culture and the ongoing development of cultural forms, and analyzes this development as a constant and continuous evolution (Boas, 1992).

In order to remain sustainable, such a tradition of making needs to be practiced. The technology of bobbin lace making needs to be able to develop in order to stay alive and be attractive to new admirers who, in turn, will be applying it and handing it over to the generations to come. When new technical combinations are being applied and range of new applications, unknown so far, are being discovered, this activity can be promoted to audiences who have not taken notice of it so far. The presentation of the idea of lace, not just as the history of the practice or an analysis of the final products, but also as a current human activity, would attract the attention of a wider circle of researchers. In his way, the opportunities for communication outside the traditional communities are increased to attract more carriers of the skill and thus keep its development alive. 
The use of interdisciplinary approaches makes possible the study of different manifestations of human culture and art, intertwined in one object. In this way, the problems related to the preservation of this traditional technology could intrigue cultural professionals who have not been familiar with this issue so far. Interpreted from the perspective of Model Theory, lace can be seen as theoretical model in a range of crosscuts. The theoretical model is "distinguishing itself first from the type, and secondly from the example", it "suggests modelling, plasticity" and "has its own potentiality" (Tenev, 2012).

In his reasoning related to Model Theory in literature, in his Poetics of Models, Robert Erdbeer poses the questions whether there are "models external to literature, which direct the poetic discourses under the guise of fiction" and whether this "blurs the demarcation between them?" (Erdbeer, 2014). If borrowed from the field of literary theory, these questions might become the justification to look into the models that exist in lacemaking and thus discover common models in other art forms and human activity. A careful study of the processes of making lace will demonstrate clearly that "a different model is always possible, that possibility has not been exhausted with the model." (Tenev, 2012)

What exists invariably and can be presented as a model can be considered from several different points of view. On the one hand, there is the technology for creating matter. On the other hand, one can look for the cultural and social significance of the creation process, as well as the influence of fashion on the consumption of lace and the creation of new patterns. And thirdly, to find patterns in the behavior of people of our time, in the making of lace, but also in collecting, using it or the aesthetic pleasure of observing lace products.

\section{Models in the technique of bobbin lace making}

Lace making is a complex activity. The results are varied and diverse. Applications are endless. Finding the common ground between these requires idealizing separately the different aspects of the considered stages of the processes and finding the models that exist in them.

What is more, shedding all the details happens gradually, until what is constant remains. The creation of any specific texture requires a model of behavior on part of the instruments. "The model will be what allows the potentiality not to be neglected by trying to keep it as a potentiality in an attempt to make any analysis a derivation of a private theory." (Tenev, 2012) This assumption can explain the wealth of options when repeating the same movements where by replacing just one (added or removed) movement, a totally different nature of the texture is achieved. 


\section{Technological model}

From the point of view of technology, the fabric is created from threads that are intertwined by their change of position: one being on top of the other and vice versa. This is achieved by the movement of the bobbins that hold the wound thread. At least four bobbins are needed in order to complete these movements. The bobbins are grouped in pairs and held in both hands. There are just two types of movements:

1) twist is when the bobbin on the right goes on top of the bobbin on the left in one hand;

2) cross is when, between the two hands, the left bobbin goes over the right one. Every beginner lacemaker starts working on patterns based on the model of these two movements. The bobbins are considered instruments as they are the place where the thread is wound in order to be moved by the hands of the lacemaker; they will not work on their own. One can do without bobbins and use the spool or hold the material in their hands, especially if it is of unusual origin and does not lend itself to winding, e.g., roots, twigs, grass, moss, or lichen.

The combination of just two movements and the change of sequence achieves an endless range of different results.

The movement of the hands leads to moving the bobbins. This leads to intertwining the threads in a certain order (left on top, right below) and in a certain sequence (all pairs of threads that build up the fabric work one after the other). These movements are repetitive. The model is discovered in the pattern of repetition. Just one increase or decrease of the number of movements can lead to a considerable change of the end result. If the maker changes the position where the pin is fixed (which, on the side, is done not between the last and the last but one pair of bobbins, but before or after the two) they can cause considerable visual and actual change of the edge which is no longer pointed but becomes even.

Experienced lacemakers discover models involuntarily. When the pattern is disturbed, they feel anxious as the departure from the routine brings about the feeling that a mistake has been made. The sequence in geometrical patterns (yard lace) is steady and one has to keep to the model in its making. When one has worked with a set of bobbins for a long time, adding just one pair of bobbins that is different in shape and size is enough and then, when the movement of the hands reaches the place where the model of movement is being changed, the accustomed hand recognizes it and knows that it is time for a change in the combination of movements. 
Seeking for models and idealizing the process is not needed for it to be perceived as a model, since repetition is present in any of the dimensions of lacemaking. In this case, several possible models are discovered on different levels. Described in line with the terminology of the model theory of Bernd Mahr (Mahr, 2011), models in bobbin lacemaking can be considered as follows:

Creating matter follows precisely the pattern which is an abstraction and a model of the ready item. The creation of the needed form and the appearance of the end product is an applicate that possesses the qualities sought by the process of making.

A model related to the technology is discovered firstly in the number of movements (number of twists), and secondly in their quality (which thread is on top and which one - beneath). If this model is accepted as an applicate, since it transfers the change of position of the threads from the matrix (the pattern that most lacemakers call a "model"), which sets the model of the sequence of change, and creates the fabric, which can be said to represent an applicate.

This model is easily discovered by the random observer, even by the inexperienced one who witnesses lacemaking for the first time, e.g., a visitor at a demonstration of the skill.

Finding a model in the end product is more challenging. If this is the applicate that we have achieved, and it is seen as an object lending itself to interpretation, as a result of its comparison to other similar items, and with the change of viewpoint, one can already seek regularities among similar objects serving different purposes. If in this example the pattern becomes real lace, afterwards, different lace results may be considered and then the situation can be compared with similarities in another area of schematizing. For example, just as from the town map one would form an idea about the positioning of the buildings and streets in the actual town, one can compare different towns by looking for shared regularities in their construction to analyze their distribution or the ways they function. A valid statement here is that "variability is a quality of the model..." and "can be used for its expression." (Tenev, 2012)

More specific examples of models related to the technology of creating fabric can be discovered in every change. In addition to the zig-zag movement, lacemaking can happen in the diagonal of the resulting band. In this case, one works always starting from the same side, no matter where they begin - left or right. This brings about additional technical opportunities, new practical solutions, and interesting visual results. The change of direction of the movement requires a different type of behavior when making a corner. 
In the case of more complex figures that require a combination of movements, one needs to have precise instructions for the work of each pair of bobbins, to be aware of the logic that is followed, and the overall idea. In this case, a model that has already been made is used, which represents a case of changing the direction of perceiving the model. "According to Bernd Mahr, each item can be a model (which is one instance of criticism on the part of Vartovski) and at the same time - nothing is necessarily a model. In order to find a solution to this problem, one has to reformulate the question - one should ask what "justifies accepting something as model." (Mahr, 2011) The answer given by Mahr's text is that this is the exact reason for which it is a "model for" - its purpose" (Teodosieva, 2017).

In each of the specific work patterns a model of making can be discovered. On the one hand, this is the repetition of groups of movements. On the other, the elements made are identical, too. There is a model of behavior in the movements at any level of work. For example, to ensure that all technical requirements are met, one needs to pull the threads tight and avoid leaving any lax sections of the thread to make sure that after the removal of the pins the figure will not be deformed and the model will be preserved.

This lacemaking technology can be used to produce a random number of the same items that will not differ from one another due to the strict production rules. To depart from the exact repetition, just one of the circumstances needs to be changed, e.g., the thickness of the thread or the material it is made of, and the final result will be different already.

Disturbing the model of behavior for practitioners happens upon the influence of the type of the working base - whether they use a "carreau" (flat pillow) or a cylinder (drum, pillow). Although it does not affect the end result, the base is of great importance to the everyday habits of practitioners. When working with a flat pillow, the bobbins are held from above, while when working with a cylinder, the bobbins are held from below in the palms. When swapping workplaces, lacemakers from the two groups shared that they felt as if their hands belonged to someone else. There was the expectation that one would be able to adapt easily after the long-term experience, but instead, they all felt blocked. This is why certain models of working with the bobbins need to be followed. Also, instead of making one additional final twist or cross, like when working on a cylinder, when working on a flat pillow, the last movement is left for the beginning of the next group of movements, since it would fall apart and would impossible to keep if left last. 
Observing similar requirements related to the end result, characteristic of a certain period of time, has led to perceiving the appearance of lace as belonging to a certain stylistic group.

\section{Models in the resulting fabric}

The analysis of the already tangible lace, applied with an idealization of all possible artefacts, defines its construction of condensed and loose-textured areas as its main distinctive feature. These areas form figures which are perceived in a complex way while observing either one or the other. Without this, lace cannot be lace, even if it is made in the same way with the interweaving of threads wound on bobbins. The contrast between airy and transparent (when the fabric is missing), and thick and opaque (when the fabric is there), is the main feature of lace. It is the transparency that distinguishes lace from its closest relative - textile. Depending on the color, background, contrast and lighting, the observer sees different aspects of the image.

The model of creating lace patterns has been studied, and it contains repetition too. The process of the development of the technology demonstrates certain regularities that guarantee better quality of the product and reduction of the production time. Models become more complex due to the growing competition and also due to the expansion of lace applications. The production stages follow models of sequences which lead to higher technological efficiency.

Here is an actual example: a point of idealization of lace is the initial drawing, which is just an idea or an image of the fabric to be. The artist/designer creates an image (model), which becomes the model for the experienced practitioner. This can be seen as an empty premise or a starting point. The model to be followed is created by an artisan who, based on the designer's project, puts into practice specific form, color, size, density. Thus, they take into consideration the requirements of the work process such as the density or the direction of the work. In this way, they recommend certain specific models of activity. They create a model to be re-created by other lacemakers. This model has kept the main elements, but contains also some changes, related to the technology involved in the implementation. The details are made specific - the number of threads, their thickness, their type (smooth or rough, synthetic or natural), the technique (interweaving) to be selected in the making. These are a set of models that are interconnected and together create the general appearance of the future fabric.

Another example of making a lace product will serve as an illustration of Darin Tenev's statement that: “The model, unlike the type, is always one of many." (Tenev, 
2012) The model is usually distributed together with specific instructions. A contest entitled Wonder Bird was held in 2015, in the town of Vologda - a Russian center of lacemaking. The model for the contest was created by Russian artist Zubareva (Fig. 1). The drawing follows the traditional aesthetics of Vologda lace. There are options to achieve an individual implementation. A specific version of the model is the one on Figure 2, made by Bistra Pisancheva by following strictly the contest regulations determining the size, shape, and some of the technical elements of the item. Participants in the contest were given the freedom of choice related to the color, thickness, and composition of the thread (Fig. 3). The number of the contestants was 350 and they all presented different implementations, with no two being the same.

Here, again, we are left with the question: can copying a model create art if a creation "becomes a work of art only when it is technically impeccable or when it demonstrates strife towards some model of the form" (Boas, 1992).

\section{Machine production}

The models produced by a machine are exact copies of the ones made manually. The way the threads are intertwined is similar and the end result is indistinguishable, if the model is the same. The models that can be produced by machine, are repeatable and symmetrical. In manual work the combinations of the two movements (twist and cross) are endless, and it is possible to have a range of styles in one product.

In machine production, no mistakes can be made, as a strict model of movement and a sequence of the bobbins is being followed.

The difference between the instruments used in manual work and the lacemaking machine is so radical, that it is difficult to find similarities in the processes even by experienced lacemakers. The ingenuity of engineers who managed to capture the model of the movement as early as the 19th century is impressive.

Lace figures are encoded in the holes of the punctured cards (Fig. 4) which determine the movements of the mechanisms. The path of the bobbins is not from one hand to the other, instead they follow the grooves (Fig. 5) which take them along the road of the same twists and crosses that are made by hand. Machine production spares lacemakers their hard and repetitive labor, by producing quickly and less expensively the miles of lace needed by the fashion of the time for the elements of ladies' underwear.

\section{History of the change of models used for the production of lace}

In the 19th century, the machine was an innovation, and the model of the traditional opposition was human/machine or hand-made/machine-made. Man 
created the machine based on the model followed by the hands and again, man created the model to be followed by the machine, adapted to the possible movements and (the significant) limitations because of the principles of construction.

In the 19th century, the production by human hands - not only of lace, but also of textiles, embroidery, knitting, as well as other handicrafts - represented a diminishing part of all manufactured products. Laser technologies and programming have now given rise to all sorts of lace which resembles the model in terms of style, figures, and general appearance. The general principle of "dense - loose" has been kept, but the technology of production has been changed completely. There is now the 3D printer which can produce anything based on a supplied model.

The development of lace has been parallel to the development of clothes and costumes. The laws (and dictatorship) of fashion require following the relevant model of the time. Even if a reference to the retro models is sought, there is always something new added, such as change of material, color, or application. When, at the end of the 19th and the beginning of the 20th centuries, fashion turned lace from an obligatory into an unwanted element, people turned to making lace items to decorate their homes. Half a century later, with the evolution of home decoration, lace napkins and other similar interior applications of lace have become obsolete.

\section{Original models}

This example of the creation of own models of clothing (Bistra Pisancheva) with lace, describes the models followed in the process of their planning and implementation.

These items of clothing were created for the purpose of a fashion show during a lace festival and exhibition in one of the lacemaking centers in Northern Spain the town of Camariñas. Making these dresses again is impossible because of the improvisation involved in their making. And yet, there are models that have been followed in the creation, that contain an aggregate or a combination of thresholds.

Instead of a cylinder, a torso - a model of the human body of the size and shape of the bodies of the living models who were to wear the clothes for the fashion show - was used. This allowed for the lacemaking to happen as if using a cylinder. The torso was made of paper pulp pasted on a model of a human figure and was filled with sawdust for easy fix of the pins. It is possible to construct a model for a piece of clothing using the traditional cylinder, but the model then needs to be made of different parts, previously designed as clothing patterns adjusted to the relief of the body. A specially designed model of the working base allows one to ignore the limitations of separate parts when depicting the drawing, to avoid symmetry and 
rules, and for the figures to move from one segment to the other without the limitation of patterns. The model chosen is free, i.e. no previously created lace model is followed. There is a clothing model that has been identified and will be implemented (Fig. 6 and 7). This represents a decision for: the shape of the dresses to include a bodice and a wide skirt made of natural silk; the material that the lace is made of to be natural silk with contrasting thickness; the colors to represent the stages of growth and development of wheat: green - golden, young - ripe; the grains to be made of "tallied leaves" made of thick silk; all stalks to be made using the element of "linen/basic work" which produces even sides; the leaves to be thin and pointed, and not to be fully fixed to the base; "young wheat" to feature both grownup shoots and ears, while the "ripe wheat" to have irregular endings like stylized harvested sheafs spread in different directions.

Here, a model of a human body has become a model for the implementation; a model of wheat plants - a model for the repetition of each separate ear of wheat; the wheat grains are placed in positions defined by the model - in the upper part of the dress. Depending on the choice of which modeling to apply, an analysis of each abstraction can be made, according to its limits and possibilities, which are different for every person.

\section{Historical change}

The evolution of culture connects lace production with the model of development of the history of art and costume in the period from the 16th to the 19th centuries. Being an obligatory sign of social and financial wellbeing, lace is decoration (Carmona, 1981), luxury, and a whim, even the reason for bankruptcy, as it is extravagantly present in the life of aristocrats "from the cradle to the grave". This mass consumption reveals "... a controlled influence of the model, i.e., some common form of behavior... The interpretation of the model can be changed, but its form stays on for long periods of time." (Boas, 1992) This type of model in clothing has remained in the past.

\section{The provocations of the current age}

The so-called Model Theory or Theory of Models, applied in mathematics, logic, semantics, and linguistics, "understands the model as an interpretation" (Tenev, 2012).

A range of models can be discovered in the lace produced nowadays. Depending on the observer and their competency in discovering their threshold of meaning, a whole bunch of thresholds can be suggested. The essence of lace - it is being a fabric 
- remains unchanged, while it keeps alternating between gauzy and tightly-knit. From the tiniest detail to a bird's eye view or from a general view to the building-block details - any aspect demonstrates the transfer of a model which preserves certain basic qualities, creates some new, and omits some already existing. As Darin Tenev notes: "the character of the model does not presuppose countability. In other words, there cannot be a finite number of models." (Tenev, 2012)

Designer Jose Luis Luaces form Galicia, Span, creates items of clothing using traditional bobbin lace which has been made in the region for centuries. His use of traditional lace, however, provokes by the place (where) the lace is placed, and also by the way (how) it is used (Fig. 8). Thus, the designer's ideas are implemented in new models, which proves that ".. in the theory of models, the actual models often appear like actualizations of the inherent possibility." (Tenev, 2012) What is usually hidden under the crinoline, is here put on display. The rest of the sets from the collection clearly demonstrate this new state. Although there is nothing unusual or innovative about the combination of lace stripes as garters or on the edge of the underwear, the overturning of the model through the symbolic partition of the crinoline agitates the audience.

Young Bulgaran designer Lidia Suteva discovers applications embodying diametrical differences between the traditional use and the possibilities in clothing nowadays. In her MA thesis at the National Academy of Arts in Sofia, Bulgaria, she offers a range of transformations of lace properties (Fig. 9). She follows the model of traditional crafts by making herself each of the knots in the traditional needle lace called "kene", dyes her fabrics with natural ingredients using old techniques, follows old models of needle lace found on the underdresses of traditional costumes from the Kjustendil region, and uses natural unprocessed silk threads for the lace. The traditional models are transformed beyond recognition while the repetition has been avoided. As Darin Tenev notes, "No theory can remain unchanged after it has met with a work of art." (Tenev, 2012)

Modern lace can take the form of improvisation, creating lace landscapes with colored threads, discovering individual ways to achieve volume, or using unconventional unprocessed materials from nature. Achieving the play of colors when shifting the threads, alternating contrasting thickness of the threads and mixing textures for different purposes offers an alternative application of the lace technique.

The pre-drawn model, which is followed to the last detail, suggests a certain way of thinking. Most lacemakers use models which do not belong to a particular author. They find them in magazines and books, download them from the internet, exchange them with peers, or attend courses where they receive detailed instructions 
about each move. Some of them are reluctant to think about the process, others are very diligent. They follow the accepted model of work. The inability to create something new, to think in a novel way, or transcend the usual, make people seek models created by someone else. To a certain extent, there exists a shared way of thinking that it is impossible for the common lacemaker to create models, that most practitioners lack imagination, that an artistic background and understanding of composition are needed.

The conversations between lacemakers most often concern the exchange of models. The sales of models printed on card are doing better than the sales of materials or tools, and even better than the sales of the final lace products. The implementation of a model carries an implicit excitement because of the need to figure out the ideas of its creator, while the lace product is just an object.

Nowadays, making lace is mostly a pastime. It is possible to make a living by teaching lacemaking, but it is difficult to sell the items produced. The process of production of even the smallest of models, e.g., a souvenir, is lengthy, as it requires years of preparation to master the skills and hours to prepare the materials.

\section{Models in the technology}

When comparing the patterns of implementing the technology, the following differences can be distinguished.

From the point of view of traditional production, creating lace works requires the participation of a range of professionals: an artist to create the model, a specialist to be responsible for the technical implementation, a tailor to combine the lace with fabric so that a piece of clothing or an accessory is completed, and a customer usually a well-to-do person of high social ranking.

The perfect samples from the past, some of which are of a quality unachievable by contemporary lacemakers, are an excellent illustration of how intensive, brave, and continuously lace developed and improved in its heyday, in the period from the 16th to the 19th centuries. "The same stability of the model can be observed in the human works of art. When a certain type has been already established, it exerts a strong influence onto the new artistic attempts... similar forms... dominant influence of a given model." (Boas, 1992)

The model used to exclude any freedom of implementation that the artist has today. We are now striving to individualize the model. When one makes improvisations in the course of work without a model, the common, which always remains, is the movement of the threads, this time lacking the limitations of repetition which was characteristic of the previous models. 
When improvising on a landscape by Paul Cézanne (Fig. 10), I follow the model of the painting by preserving the colors and shapes of the original; I select and consider the color, types, thickness and material of the threads. For the implementation and intertwining of the threads, I have my inventions of how to alternate them, how to distribute them to avoid order, how to avoid any instance/danger of rhythm or repetition, in order to achieve an effect that is alive and touches the observer.

Contemporary artists rely mostly on a combination of their own skills. Belonging to a school or region is not so much in demand as the individual style that creates unique artefacts. Ana Rosa Lista from Santiago de Compostela in Spain makes lace images of the architectural landmarks of her town, while Mira Fidanza from Locarno, Switzerland, makes abstract net compositions and calls her lace "genetically modified".

\section{Conclusion}

In conclusion, we should notice that for the people who are not familiar with lace and the way it is made, representing the making and the works as a theoretical model might seem inappropriate. For those, who are familiar with the cultural practice, this will be interesting and yet, unusual. Claude Lévi-Strauss writes the following about a similar situation: "It is true that we can create many models - different, but convenient, for all sorts of things, in order to describe and explain a group of phenomena." (Levi-Strauss, 2015)

The representation of lacemaking as a model of technological processes, of lace items, and a community of people who practice this handcraft, could contribute to the preservation of this part of the immaterial cultural heritage of humanity. Approaching the topic from a non-traditional perspective might increase its chances of survival and support the promotion of old-times arts and crafts.

\section{References:}

Boas, F. (1992). The art of depiction, ABC of ethnology, anthology of science for man, culture and society. Vol. 1. Sofia. (in Bulgarian)

Erdbeer, R. (2014). Poetics of Models - Reflections on a Theory of the Model in Literature. Literary Journal, 37. (in Bulgarian)

Levi-Strauss, K. (2015). Structural Antbropology. Vol. 1. Sofia.

Tenev, D. (2012). Fiction and image. Models. Plovdiv. (in Bulgarian) 
Teodosieva, H. (2017, December 7) The Theory of Models as a Way for Understanding Literary Identification, Philological Forum Magazine. Retrieved November 11, 2020 from https://philol-forum.uni-sofia.bg/theory-modelsliterature-identification (in Bulgarian)

Mahr, B. (2011). On the Epistemology of Models. In: Rethinking Epistemology, G. Abel, J. Conant.

Carmona, M. (1981). Marie de' Medici s. Paris: Fayard. 


\section{Appendix}

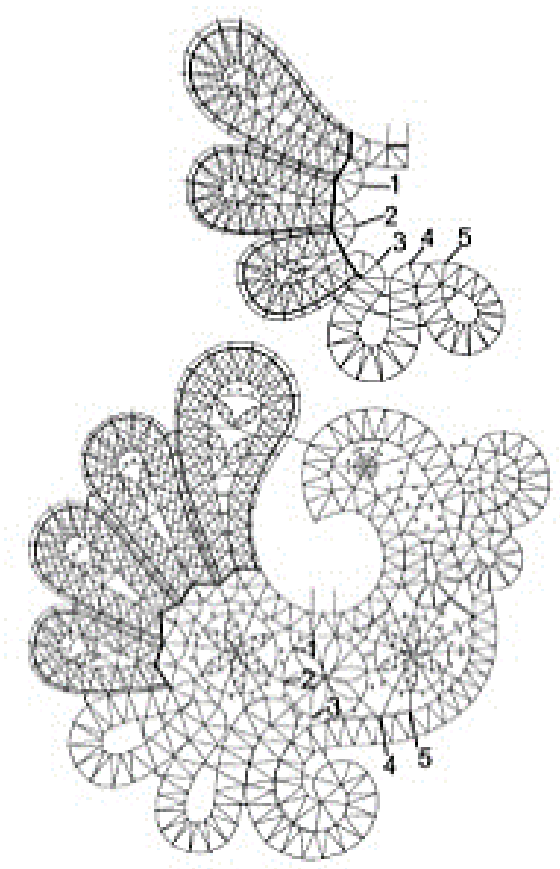

Figure 1. Model by Zubareva, provided by the contest in Vologda, Russia

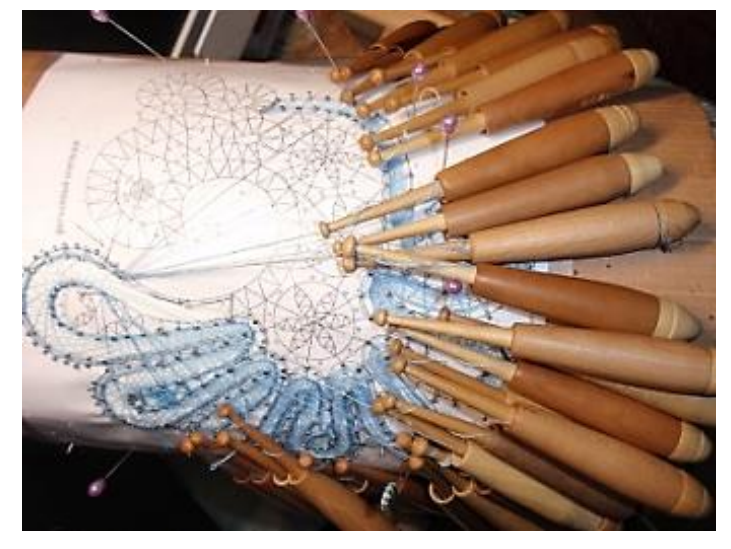

Figure 3. Model of a bird, rendered by B. Pisancheva

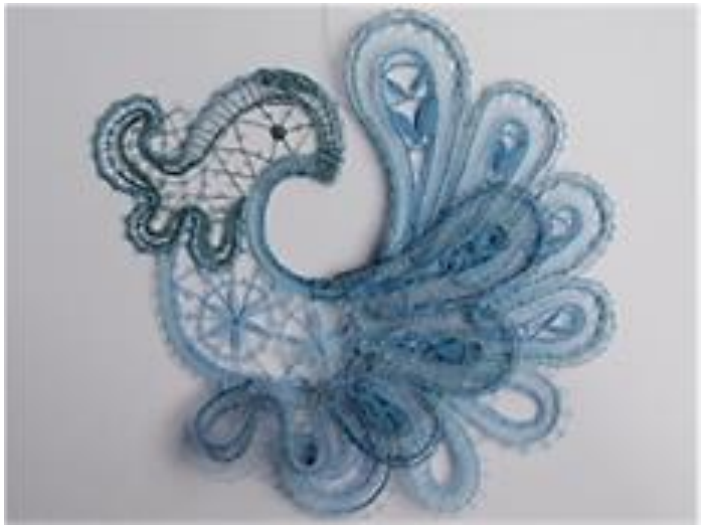

Figure 2. Making lace following a model 


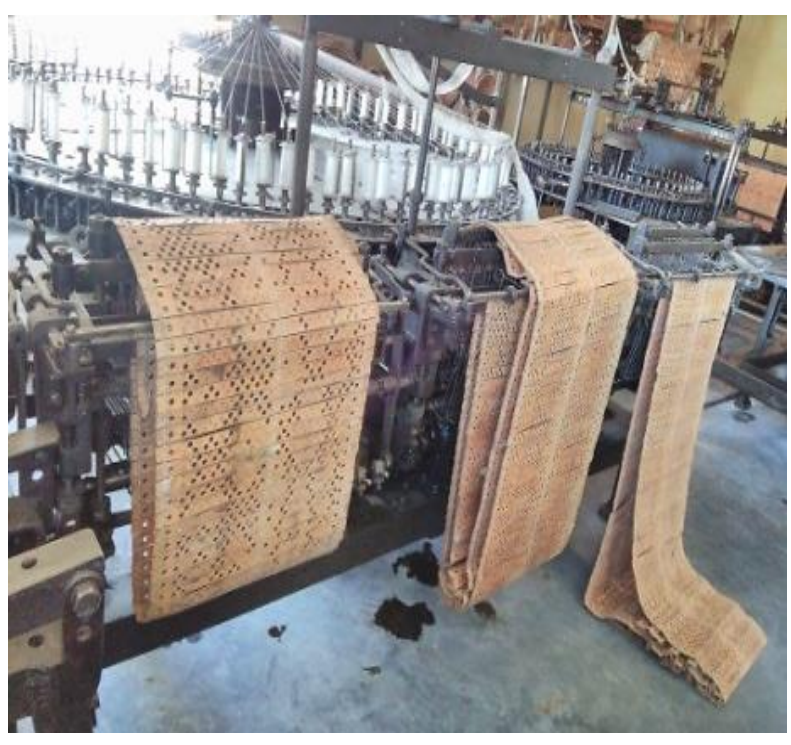

Figure 5. Lacemaking mechanism with punctured cards

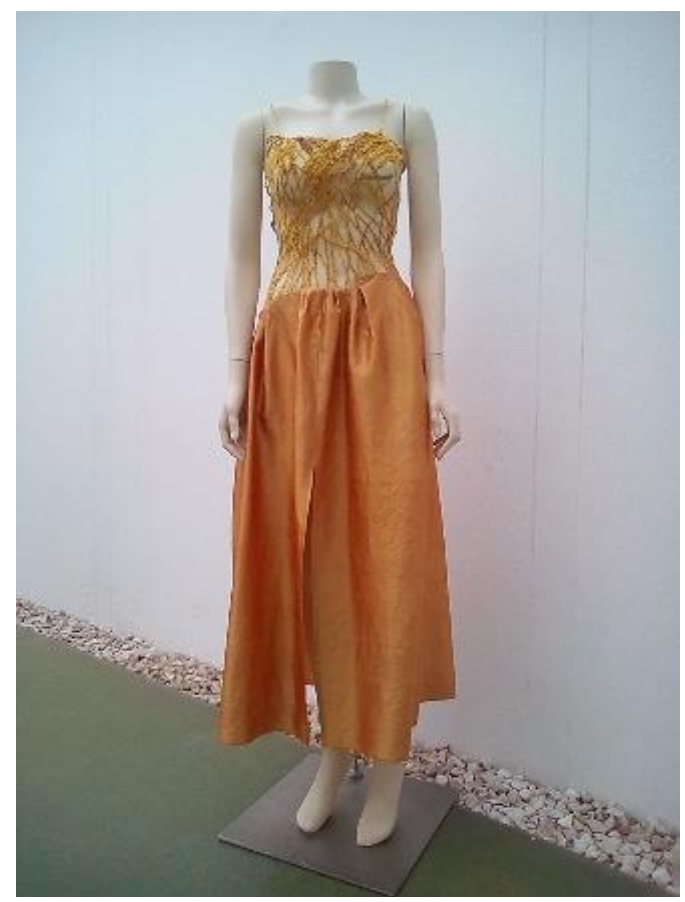

Figure 6. Ripe Wheat dress, B. Pisancheva

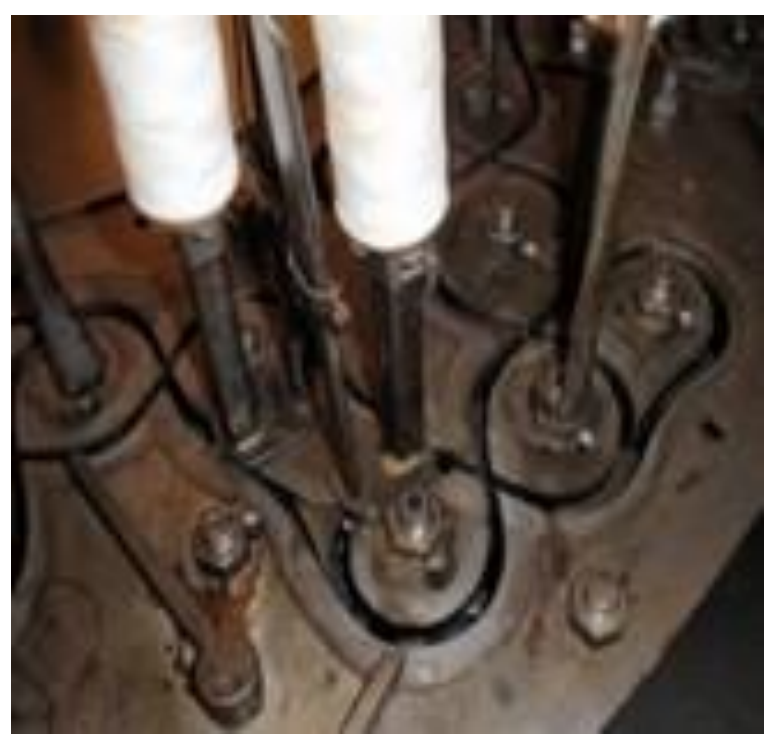

Figure 4. Mechanism detail - grooves and paths of bobbins with thread

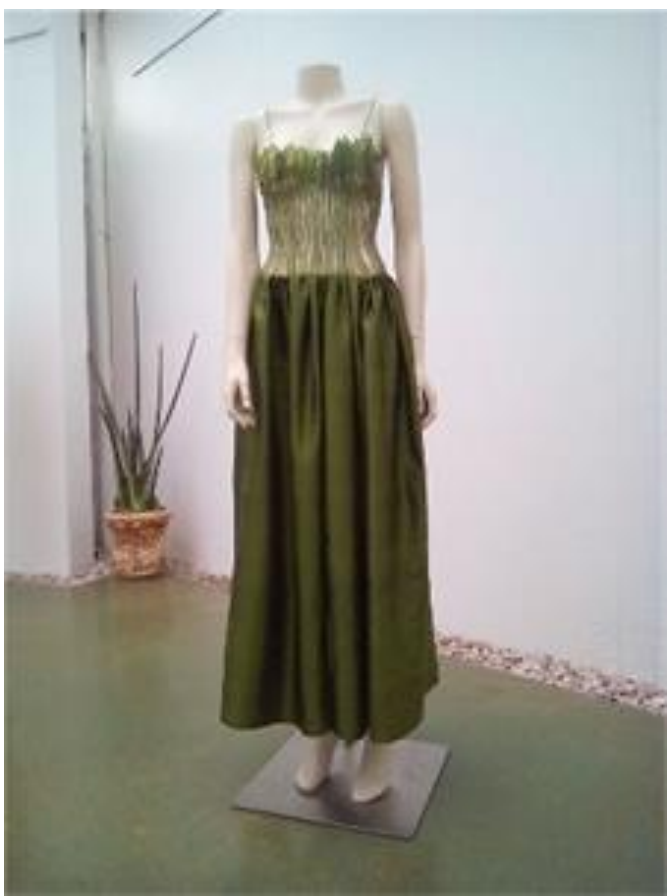

Figure 7. Yong Wheat dress, B. Pisancheva 


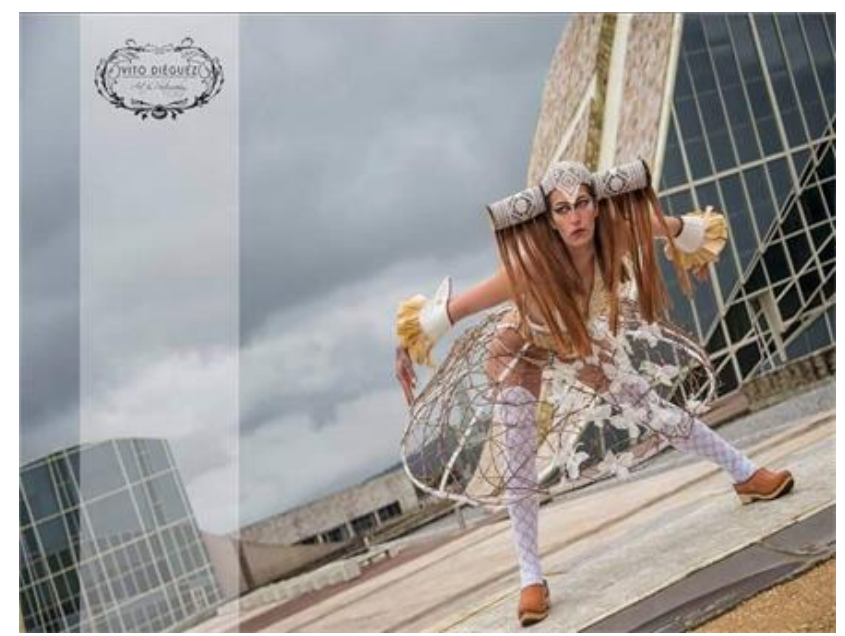

Figure 8. A model by Jose Luis Luaces
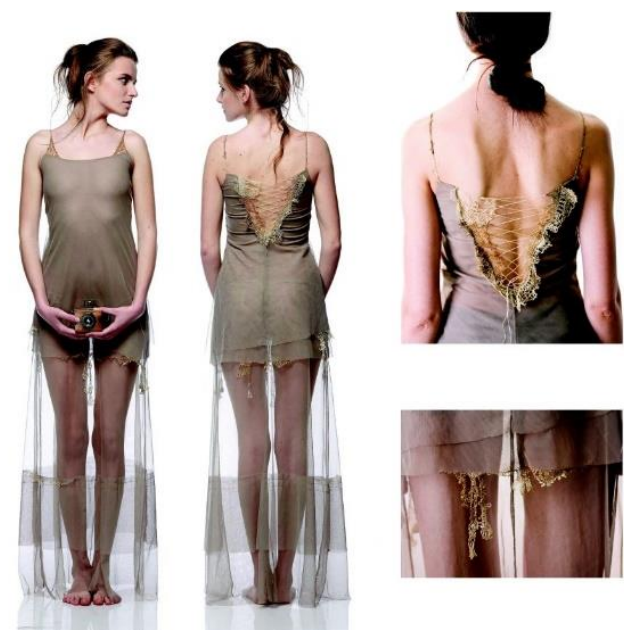

Figure 9. Models by Lydia Suteva

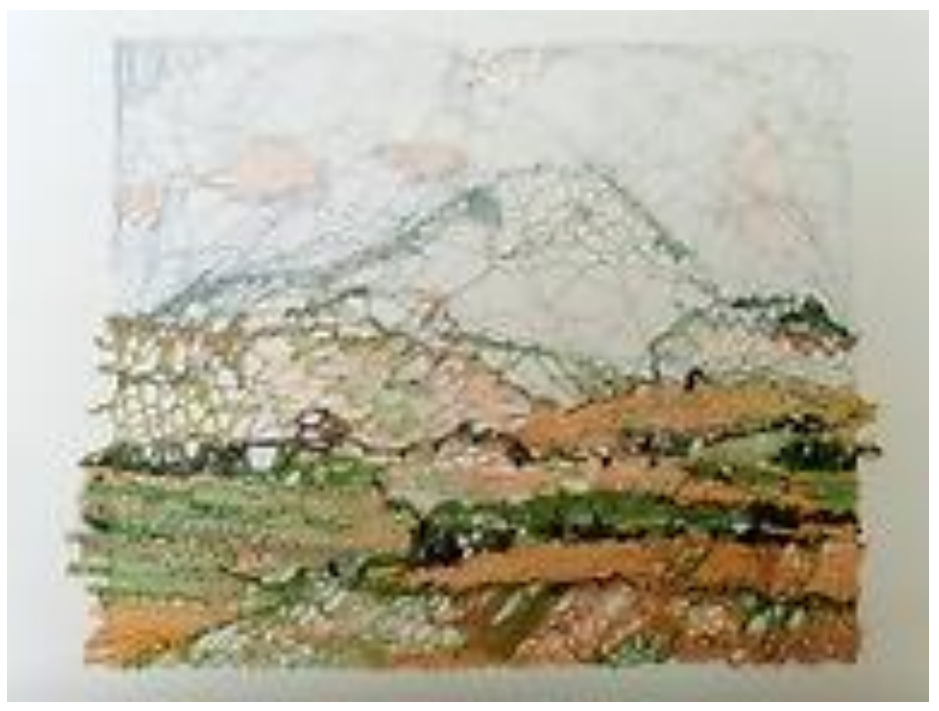

Figure 8. A painting by Paul Cézanne rendered in lace, B. Pisancheva 